\title{
A Study on the Population Structure of Democratic People's Republic of Korea
}

\author{
Saebom Jeon ${ }^{a}$, Seong Eun $\mathrm{Kim}^{b}$, Yousung Park ${ }^{1, c}$ \\ ${ }^{a}$ Department of Applied Statistics, Korea University, Korea \\ ${ }^{b}$ Economic Statistics Department, The Bank of Korea, Korea \\ ${ }^{c}$ Department of Statistics, Korea University, Korea
}

\begin{abstract}
The re-unification of the two Koreas is seen as a potential solution to the aging problem and low fertility, along with the increase in the old population structure of the Republic of Korea. Population structure is an indicator of national competitiveness or growth, but little is known officially about the populations of Democratic People's Republic of Korea (DPRK). Understanding the population structure of the DPRK is important to prepare for re-unification and estimate the socio-economic costs of national welfare under a re-unified Korea. In this paper, we assess reliability of the two modern national censuses of DPRK and use the limited resources available to reconstruct the intercensal populations between these two censuses. Excess deaths from the 1995 famine are estimated at 489,972 to 574,306 and are close to the estimates of Goodkind et al. (2011) and the reconstructed populations in the of DPRK implies a big difference between two Koreas.
\end{abstract}

Keywords: Military population, assessment, model life table, reconstruction, excess deaths.

\section{Introduction}

Koreans have dreamed of reunification since Korea was broken into two in 1948. Different political, economic and social systems stemmed from the division of Korea during the past 57 years necessarily bring the different vital statistics and population structures. The levels of vital statistics (like fertility and mortality) in a country reveal national living conditions such as child nutrition, health, medical services, and social insurance and welfare. Population aging in the population structure is also a basic indicator that indicates the potential for a country's growth; therefore, understanding the current and future population of two Koreas is an important task for a unified Korea.

Official population statistics for the Republic of Korea (South Korea) have been published every five years with scientific accuracy and reliability; however, little is known about the Democratic People's Republic of Korea (North Korea) with only two published modern national censuses in 1993 and 2008. Compared with the 1993 census which is the first census ever taken in North Korea, the 2008 census was reported as much improved (Engracia, 2010). In addition to these two censuses, North Korea occasionally released crude death rates and life expectancies in 2003, 2004 and 2005 by Reproductive Health Surveys (RHS, DPRK Central Bureau of Statistics, 2000, 2004, 2007), conducted in

\footnotetext{
The research reported on in this paper was partly supported by a Korea University Grant (Grant \#K1420791) and partly by a National Research Foundation of Korea Grant funded by the Korean Government (NRF-2013S1A5B8A01054750).

${ }^{1}$ Corresponding author: Department of Statistics, Korea University, Anam 5-1, Seoul 136-701, Republic of Korea.

Email: yspark@korea.ac.kr
}

Published 31 January 2015 / journal homepage: http://csam.or.kr

(c) 2015 The Korean Statistical Society, and Korean International Statistical Society. All rights reserved. 
collaboration with the United Nations; however, the reliability and quality of the population statistics remain questionable (Goodkind et al., 2011).

This paper is to understand the recent population structure of North Korea between 1993 and 2008 based on the two censuses and vital statistics. This paper addresses two issues: first, we discuss how to reconstruct the intercensal population of North Korea between 1993 and 2008 with the limited population resources. Second, based on the reconstructed population, how many people died from the famine of 1995 to early 2000's when the Soviet Union began to cut economic aid along with a series of floods and the collapse of heavy industry (Goodkind and West, 2001).

Research on population trends in North Korea have been rarely published due to limited population information. Adlakha and West (1997) projected sex-specific total populations in North Korea using annual age-specific death rates from the famine related experience of China's Great Leap Forward (1958-1962). Goodkind and West (2001) offered population trend and life expectancies for 19942000 in North Korea based on the official crude birth and death rates for 1995 and 1998 (published in 1999 by North Korea) and information from North Korea famine refugees in China (Robinson et al., 1999). The research indicated that the number of famine-related deaths between 1995 and 2000 were $600,000 \sim 1,040,000$.

We will temporarily use the life expectancies of 1994-1998, provided by Goodkind and West; however, we will show that their life expectancies were over-estimated, in terms of the extent of the consistency between populations constructed from 1993 and those from 2008. Lee (2004) estimated that the total number of famine deaths was 580,000 690,000 from 1994 to 2000 using the population component method under the closed population assumption (i.e., no international migration). The estimates were revised downward to 500,000 and 600,000 (Goodkind et al., 2011) and to 240,000 and 420,000 (Spoorenberg and Schwekendiek, 2012).

Statistics Korea (2011) conducted population estimates and projections and released the material in the report "1993-2055 Population Projection of North Korea". However, it did not provide detailed methods for population estimates. First, it reported that North Korean life expectancies of were 59.5 for males, and 66.4 for females in 1998 without providing any methodological reason or references. Second, it reported an adjustment of the age-specific population using survival rates from the life table without adjusting the omitted military population in the 1993 census data. Third, it extended the open end age of the 2008 census from $80+$ to $100+$ by assuming that the mortality pattern of 2008 was the same as 1993 . However, the mortality pattern seems changed, probably due to the famine-related excess deaths as shown in the life expectancy pattern.

Comprehensive analysis for the North Korean population was offered by Spoorenberg and Schwekendiek (2012). They demonstrated that official vital statistics (such as fertility and mortality) were reliable according to the consistency of the reconstructed and observed 2008 populations. They also estimated the total number of excess deaths caused by the famine in the 1990's as between 240,000 and 420,000. However, their approach to reconstruct populations between 1994 and 2007 has a drawback by assuming that life expectancy returned to the 1993 level in 2000. This resulted in a three year life expectancy decrease from 2000 and 2008 but it is unrealistic without an explicit event or natural disaster during the period and is also contradicted by empirical evidence that shows notable improvement in child malnutrition for 1998-2009 and improved health at all ages (FAO/WFP, 2010; Figure 6). The government of North Korea released life expectancies at birth with a mean life expectancy of 67.5 years in 2003, 68.1 years in 2004, and 68.7 years in 2005 (DPRK Central Bureau of Statistics, 2007), showing a clear decreasing trend of mortality rates. Unlike previous studies, we use these official life expectancies to construct the populations between 1993 and 2008 and project a future population in North Korea. 

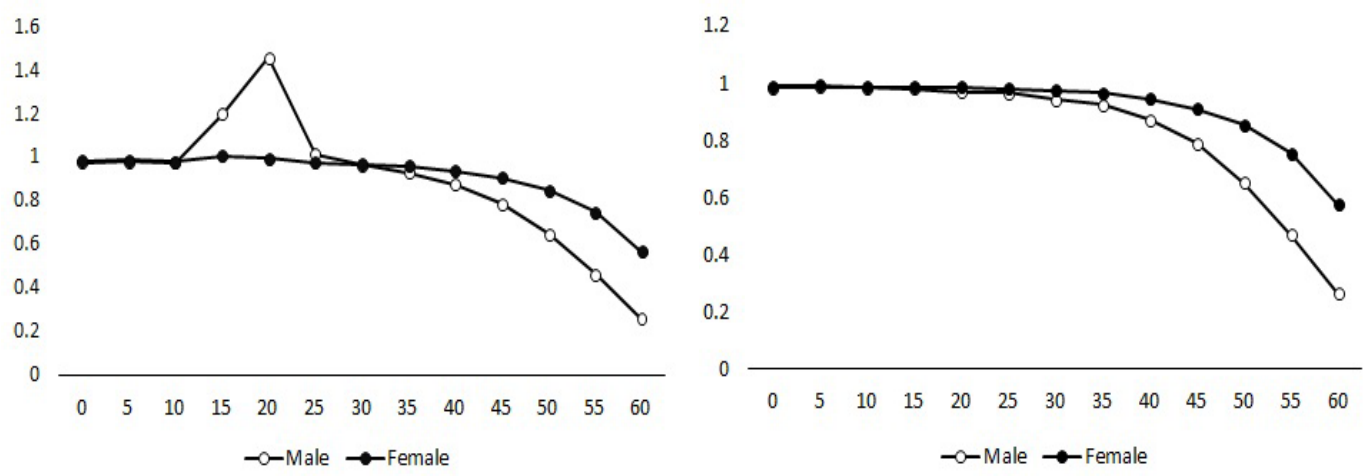

(a) original survival rates without the 1993 military population (b) adjusted survival rates including 1993 military population

Figure 1: Intercensal survival rates between 1993 and 2008 censuses in North Korea

This paper consists of 4 sections. In Section 2, we reassess the DPRK 1993 and 2008 censuses by a demographic analysis, in order to restore the military population in the 1993 census and to examine the completeness of the two census enumerations and mortality registration. We then identify the mortality patterns of North Korea in 1993 and 2008 using eleven model life tables and compare them with South Korea. In Section 3, we reconstruct the populations in North Korea from 1994 to 2007 and estimate the single age-sex specific famine-related deaths between 1995 and 2000. Section 4 includes concluding remarks and discussion.

\section{Assessment of the 1993 and 2008 Censuses in North Korea}

The government of North Korea released single-age population and mortality with exclusion of the military population in the 1993 census enumeration, while single-age population but five-year age group mortality and military population in the 2008 census. A prerequisite for population reconstruction between these two censuses is to calculate a single age-sex specific military population for the complete 1993 census data and to construct single-age mortality rates in the 2008 census.

\subsection{Military population in the 1993 census}

The 1993 census data in North Korea include the total population of 21,213,378 and single age-sex specific population; however, the sum of the single age-sex specific population is $20,522,351$. This lower total population difference of 691,027 has been regarded as the military population (Adlakha and West, 1997; Spoorenberg and Schwekendiek, 2012). As Spoorenberg and Schwekendiek (2012) suggested, we apply the observed distribution of the 2008 military population to the total number of the 1993 military population under the assumption that the distribution of age-sex specific military population of 1993 is the same as 2008 . We tabulate the resulting data with five-year age groups (i.e., 0-4, 5-9, . .60-64) which include the five-year age group population calculated from the 1993 single age-sex specific population without military population. We then calculate the survival rates of these age groups with respect to the corresponding cohort age groups in 2008. For example, a 15-19 aged male in 1993 is compared to a 30-34 aged male. The survival rates should be less than 1 as there was no evidence that international migration existed in North Korea during these 15 years.

Figure 1 shows intercensal survival rates of the 1993 population to the corresponding five-year age group cohort of the 2008 population. Figure 1(a) shows survival rates without the allocation of the 
Table 1: $R^{2}$ for model life tables on North Korean mortality data

\begin{tabular}{cc|ccccccc}
\hline \hline Year & Sex & West & North & East & South & Fareast & General & South Korea \\
\hline \multirow{2}{*}{1993} & Male & .951 & .940 & .937 & .987 & .945 & .984 & .833 \\
& Female & .842 & .862 & .865 & .962 & .868 & .938 & .743 \\
\hline \multirow{2}{*}{2008} & Male & .959 & .943 & .961 & .887 & .942 & .920 & .899 \\
& Female & .970 & .978 & .972 & .914 & .951 & .939 & .926 \\
\hline \hline
\end{tabular}

1993 military population and reveals larger survival rates for 15-29 year old men and 15-19 year old women than 1 , due to the omission of the military population in the 1993 population. This implies that most of the military population belongs to these young age groups. After allocating the 1993 military population according to the distribution of the 2008 five-year age group and sex military population as described above, the survival rates of 25-29 and 30-34 years old men still need to be adjusted. A carefully adjusted 1993 five-year age group and sex military population produces survival rates smoothly downward as the age group gets old, (Figure 1(b)).

We employ the generalized growth balance (GGB) method proposed by Hill (1987) to assess the allocation of the 1993 five-year age group and sex military population. GGB is one of most practical methods to evaluate the completeness of the census and death reporting system in a country with a closed population such as North Korea. We agree with Goodkind et al. (2011) and Spoorenberg Schwekendiek (2012) in the assumption that the 2008 census is more complete than the 1993 census. Application of the GGB method on the 15-55 age group (where most of the military populations are distributed) produces $99.3 \%$ completeness of the 1993 census for male and $98.6 \%$ for females (relative to the 2008 census) and implies that the allocation of the military population in 1993 (Figure $1(b))$ is reliable. However, the completeness of the death report between the two censuses is $76.3 \%$ for men and $33.6 \%$ for women. The low percentages might be caused by the famine that started in 1995; however, it also could be from different mortality patterns in the 1993 and 2008 populations due to the famine because the GGB method presumes that the two adjacent census population are stationary (i.e., the same mortality pattern) (Jeon et al., 2012).

We finally construct a single age-sex specific military population in 1993 from the five-year age group and sex population. This transformation from the five-year age group population to single-age group population is necessary to construct a single age-sex specific population between 1994 and 2007 and estimate famine related excess deaths from 1995 to 2000.

\subsection{Mortality and life expectancy}

Death statistics are required for demographic analysis and public health administration. The mortality pattern of North Korea can be characterized by fitting to the Coale-Demeny and United Nations model life tables (Coale and Demeny, 1983; United Nations, 1983), as well as the standard mortality of South Korea provided by Park et al. (2013) to see how related the two Koreas are in terms of mortality pattern. We apply the following Bass-logit model (Brass, 1977) to examine which model life table provides the best fit to 1993 and 2008 mortality data.

$$
\log \frac{m_{x}}{1-m_{x}}=\beta_{0}+\beta_{1} \log \frac{m_{x}^{s}}{1-m_{x}^{s}}+\epsilon_{t},
$$

where $m_{x}$ is the mortality rate at age $x$, and $m_{x}^{s}$ is the mortality rate at age $x$ from model life tables. The age $x$ ranges 1 to 60 as death rates at birth are unreliable (Spoorenberg and Schwekendiek, 2012).

Table 1 shows the coefficients of determination for six model life tables and the standard mortality of South Korea. The standard mortality of South Korea unexpectedly shows the worst fit to the mortality pattern of North Korea in 1993 and the second worst fit in 2008. This shows that the two 


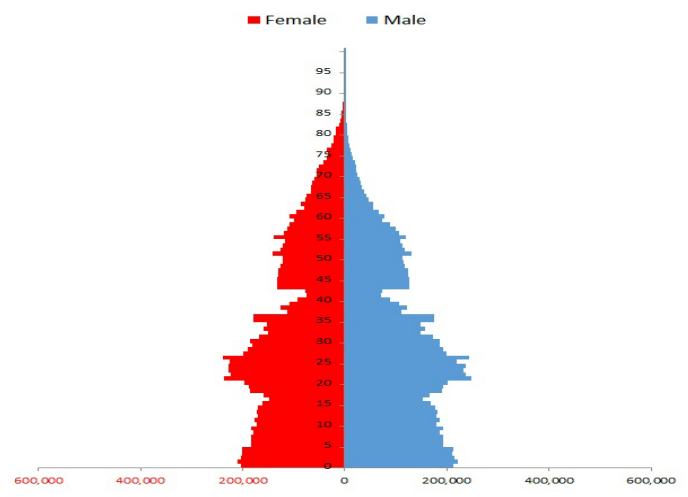

(a) North Korea in 1993

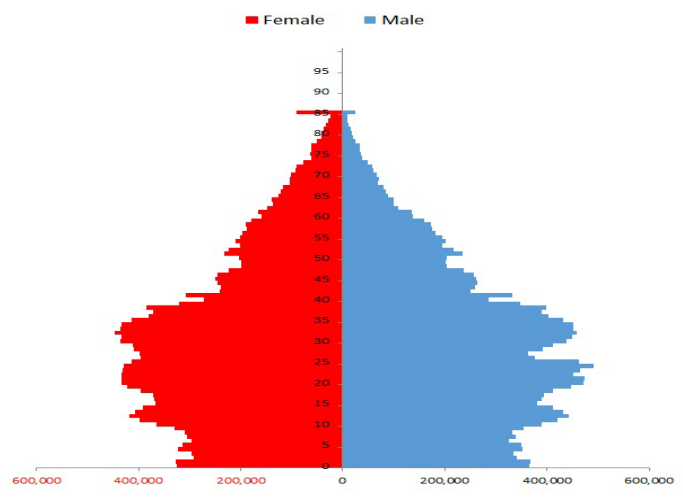

(b) South Korea in 1993

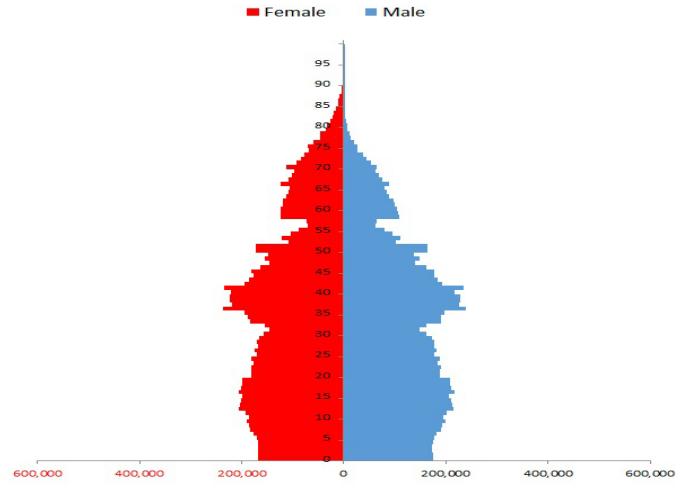

(c) North Korea in 2008

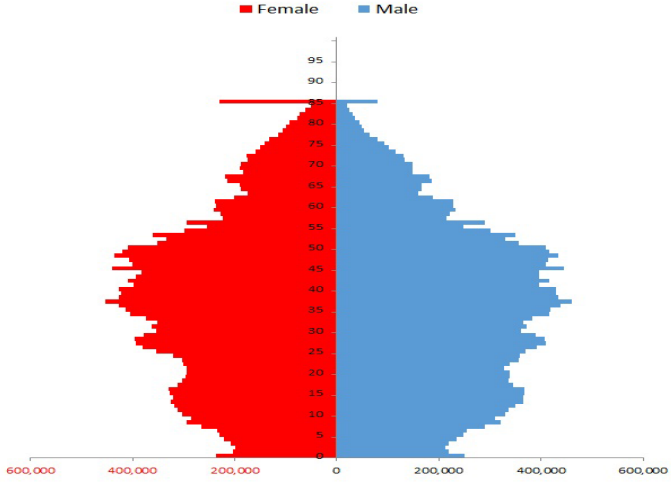

(d) South Korea in 2008

Figure 2: North Korean population trends by temporary life expectancy

Koreas are totally different countries in regards to mortality patterns and indicating that medical care and welfare system in North Korea are far worse than South Korea because the south and east types of model life tables (which show the best fits to the mortality of North Korea) are typical mortality patterns for developing countries with a high mortality of infant, children and elderly. The 1993 and 2008 population pyramids clearly address a sharp difference of population structures between the two Koreass (Figure 2).

One more surprising result is that the south type with the best fit for 1993 shows the worst fit to the 2008 mortality data; however, the east type with the second worst fit for 1993 shows the best fit to the 2008 mortality. This implies that the mortality pattern of the south type in 1993 changed to the east type in 2008 due to the famine that started in 1995, as long as one can rule out that this shift was not caused by problems in one (or both) of the censuses. Note that north type is the best for females in 2008; however, we believe that this was by chance as the north type is representative for developed countries with low mortality for infants, children, and the elderly.

Based on this observation, we assume that the mortality patterns from 1993 to 1998 follow the south type of Coale-Demeny life table; however, those from 1999 to 2008 follow the east type in constructing the population of 1994-2007 in the following section. Note that we still have a five-year age group and sex mortality open ended at 80 years old in 2008 and need to expand the mortality rates 
Table 2: Life expectancies at birth for constructing the population in North Korea

\begin{tabular}{cc|cccccccccccc}
\hline \hline \multicolumn{2}{c|}{ Year } & 1993 & 1994 & 1995 & 1996 & 1997 & 1998 & $\cdots$ & 2003 & 2004 & 2005 & $\cdots$ & 2008 \\
\hline \multirow{2}{*}{ Temporary } & Male & 68.1 & 67.7 & 67.2 & 65.1 & 63.0 & 60.9 & $\cdots$ & 63.5 & 64.1 & 64.7 & $\cdots$ & 64.9 \\
& Female & 75.7 & 75.0 & 74.4 & 72.0 & 69.7 & 67.3 & $\ldots$ & 71.4 & 72.1 & 72.6 & $\ldots$ & 72.6 \\
\hline \multirow{2}{*}{ Revised } & Male & 68.1 & 66.7 & 65.2 & 62.3 & 60.9 & 60.9 & $\cdots$ & 63.5 & 64.1 & 64.7 & $\cdots$ & 64.9 \\
& Female & 75.7 & 74.0 & 72.3 & 68.9 & 67.3 & 67.3 & $\ldots$ & 71.4 & 72.1 & 72.6 & $\ldots$ & 72.6 \\
\hline
\end{tabular}

The life expectancies denoted by $\cdots$ are linearly interpolated.

to a single age-sex specific mortality open ended at 100 years old. To do this, we extend the 2008 mortality rates open ended at 80 years old to at 100 years old by applying the Brass logit model given in (2.1) with the observed 2008 mortality rates as a dependent variable and the mortality rates from the east type as a covariate in which an the model life tables provide five-year age group mortality rates open ended at 100. We then use the Greville smoothing method (Greville, 1945) to obtain the 2008 mortality rates by single age-sex group from those by five-year age groups and sex.

\section{Reconstruction of the Population for 1994-2007 and Famine-Related Excess Deaths}

There have been two comprehensive discussions on North Korean life expectancies at birth for 19932008, using a piece of information for crude death rates and life expectancies and using the experience of Great Leap Forward Famine in China (1958-1962) (Goodkind and West, 2001; Spoorenberg and Schwekendiek, 2012). They commonly state that the lowest life expectancy occurred in 1998, three years after the onset of the famine in North Korea. This is the reason why we set different mortality types prior to and after 1998.

\subsection{Estimation of populations for 1994-2007}

We temporarily use Goodkind and West's estimates for the 1995 (the onset of the famine) and 1998 life expectancies. In order to avoid the previous unreal assumption that the life expectancy in 2000 rebounds to the level of 1993, we instead use the official life expectancies of 2003, 2004, and 2005 released in the 2006 Reproductive Health Survey (DPRK Central Bureau of Statistics, 2007). The life expectancies of other years between 1993 and 2008 are linearly interpolated as given by the first row of Table 2 and the life expectancies of 1993 and 2008 are obtained by the method described in Park and $\operatorname{Kim}(2011)$.

We match the life expectancy at birth of the south type with the life expectancies of 1994-1998 (Table 2). This match can be done by linearly interpolating the given life expectancies of model life tables. For example, the mortality rates for male in 1995 with life expectancy of 67.2 are estimated by the south type with a life expectancy of 67 multiplied by 0.8 plus the south type with 68 multiplied by 0.2 . The mortality rates are applied to Greville smoothing to provide single-age mortality rates since this represents five-year age group mortality rates open ended at 100 years old. This procedure is repeatedly applied, regardless of sex for all years from 1994 to 1998. The application of the same method to the east type for the mortality rates of 1999-2007 then provides single age-sex specific mortality rates for all 16 years from 1993 to 2008.

Let $P_{t}^{a}, D_{t}^{a}$, and $d_{t}^{a}$ be the population, deaths, and mortality rate of age $a$ in year $t$, respectively. Then the population balanced equation under no international migration is defined by

$$
P_{t+1}^{a+1}=P_{t}^{a}-D_{t}^{a}=P_{t}^{a}\left(1-d_{t}^{a}\right)
$$

Since we have complete single age-sex specific population for the two censuses, 1993 and 2008, and 


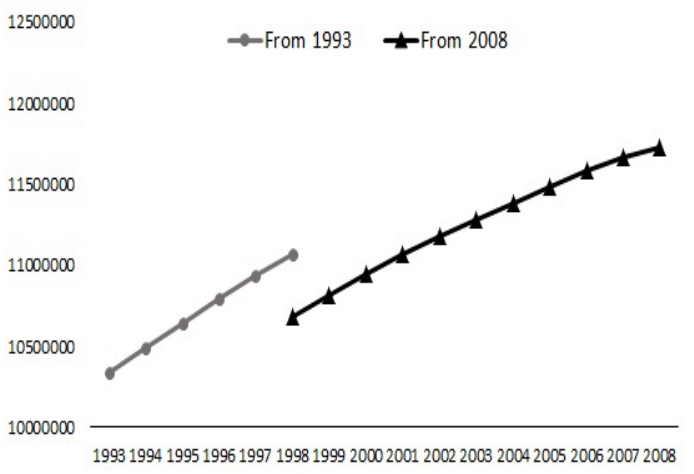

(a) Male

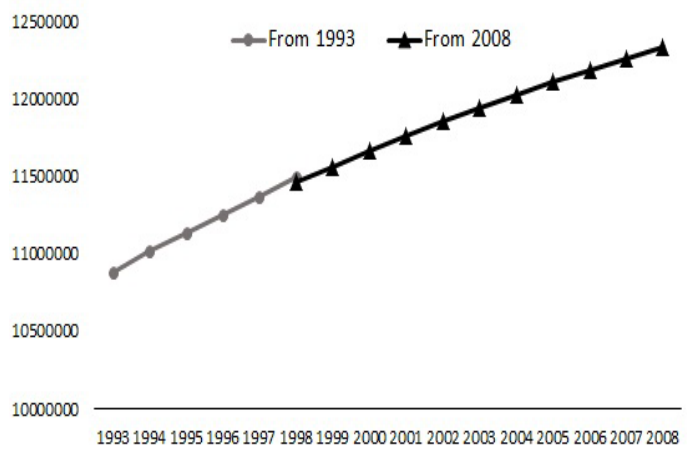

(b) Female

Figure 3: Population trend in North Korea by temporary life expectancies

single age-sex specific mortality rates for all years from 1993 to 2008, we start the balanced equation with $t=1993$ to have the population of $t=1994$, and successively apply the balanced equation until the population of $t=1998$ are constructed. We use the balanced equation in a reverse way (i.e., $\left.P_{t}^{a}=P_{t+1}^{a+1} /\left(1+d_{t}^{a}\right)\right)$. That is, starting $t+1=2008$, we have $P_{t}^{a}$ for $t=2007$ and recursively apply this balanced equation until we have $P_{t}^{a}$ for $t=1998$. Here, for the population at age 0 from 1994 to 1997, the crude birth rates officially reported for 1996, 1998, and 1999 (Moon, 2011) are used with the sex ratio at birth constant at 1.05 (Goodkind, 1999). The crude birth rates for 1994, 1995, and 1997 are linearly interpolated. Note that the crude birth rates for 1999-2007 are unnecessary because the population aged 0 is directly estimated by the population balanced equation from the population aged 1 in the next year.

This process produces two estimates for the 1998 population, calculated forward from the 1993 census and backward from the 2008 census. The two estimates show a clear discrepancy in the total population for each sex (Figure 3). This implies that the presumed life expectancies for 1994-1997 (Goodkind and West, 2001) are too high; consequently, we revise the life expectancies of 19941997 so that the 1998 total population of each sex (estimated forward from 1993 and backward from 2008) are consistent. To do this, we assume that the life expectancies of both 1997 and 1998 are the same. This assumption is partly due to some ambiguity about the onset and end of famine conditions (Goodkind and West, 2001; Lee, 2004; Haggard and Noland, 2007) and partly for convenience of the revision; however, it does not affect estimation of excess deaths from the famine, which is one of our aims in this paper. We then further assume that the mortality rates in 1995 are twice than other years to accommodate an immediate effect of the onset of the famine that yield a decline of the life expectancy from 1995 to 1996 double that of 1993 to 1998 . The second row of Table 2 summarizes the resulting life expectancies.

The revised life expectancies which produce consistent population of each sex in 1998 allow us to restore a single age-sex specific population for 14 years from 1994 to 2007 with the same approach as life expectancies in the first row of Table 2.

\subsection{Famine-related excess deaths}

Two counterfactual projections are utilized to measure impact of the famine that started in 1995 on the population between 1995 and 2000. We hold all demographic parameters in the population projection constant and only vary the mortality rate as Spoorenberg and Schwekendiek (2012) did. The first 
Table 3: Famine-related excess deaths in North Korea from 1995-2000

\begin{tabular}{cc|rrrrrrr}
\hline Mortality & Sex $\backslash$ Age & \multicolumn{1}{c}{$0-9$} & $10-19$ & $20-29$ & $30-39$ & $40-49$ & $50-59$ & $60+$ \\
\hline \multirow{3}{*}{ Lower } & Male & 44,380 & 8,240 & 17,530 & 17,508 & 16,458 & 32,697 & 55,254 \\
& Female & 78,327 & 5,978 & 11,481 & 14,710 & 14,284 & 29,651 & 143,286 \\
\cline { 2 - 9 } & Sum & 122,207 & 14,218 & 29,011 & 32,218 & 30,742 & 62,348 & 198,540 \\
\hline \multirow{3}{*}{ Upper } & Male & 72,491 & 9,451 & 20,893 & 20,113 & 18,654 & 35,545 & 65,163 \\
& Female & 91,148 & 6,962 & 13,417 & 16,573 & 15,687 & 31,645 & 157,078 \\
\cline { 2 - 9 } & Sum & 163,639 & 16,413 & 34,310 & 36,686 & 34,341 & 67,190 & 222,241 \\
\hline \hline
\end{tabular}

assumption of mortality is fixing the mortality levels from 1994 to 2000 on the mortality of 1993.

This mortality assumption produces a lower bound of famine-related excess deaths because death rates throughout the world have decreased due to advances in medicine and improved living conditions. The second assumption of mortality is a decline of $0.6 \%$ per year in the mortality rate; consequently, the average magnitude of mortality declines from 1999 to 2008. Dyson and Cormac (2002) indicated that the mortality rate is expected to rapidly decrease once a crisis like a famine in North Korea passes along with a second assumption of an upper bound of famine-related excess deaths.

Single-age specific excess deaths from the famine for each sex are estimated by subtracting the lower and upper bounds from the reconstructed populations in Section 3.1. Table 3 summarizes famine-related excess deaths for certain age groups and shows that the excess deaths from 1995 to 2000 range from 489,972 to 574,306. Female deaths are larger than male deaths; consequently, females suffered a higher mortality than males during the famine period in North Korea with famine related female deaths estimated at 297,719 to 332,513 versus male deaths estimated at 192,073 to 241,794 . The reason female deaths were more than male in any of age cohort can be explained partly because in the case of younger generations, more males were in the military and more likely to survive than females. Likewise, female seniors were less likely survive the famine due to their lack of access to resources such as food or medicine when there was a malfunctioning system of income redistribution. Additionally, infants and children deaths aged 0-9 and the old aged 60 or more occupy $25.1 \% \sim 25.8 \%$ and $38.7 \% \sim 40.5 \%$ of famine related deaths, respectively. In particular, female deaths aged 60 or more are 2.41 2.6 times higher than male deaths for the same age group. This implies that the deteriorating living conditions (due to the famine) affected females more than males, infants and children or elderly than adolescent and adults.

\section{Concluding Remarks}

We proposed a method to reconstruct the population of North Korea, with limited population resources. Inclusion of the military populations produced a smooth survival rates and quite good completeness of census, relative to the reliable 2008 census. Intercensal populations between two censuses showed a discrepancy due to the severe famine, provoking excess deaths of the elderly and female children. This severe famine changed the mortality pattern of North Korea from the south type to the east type among Coale Demeny model life tables. We estimated mortality rates and finally reconstructed the population from 1994 to 2007 based on life expectancy and the model life table. The reconstructed population showed a significant difference between South and North Koreas consequently, famine related excess deaths are estimated between 500,000 and 600,000.

Understanding the current and future population structures of both Koreas is a salient task required for a unified Korea. Our future work will include a population projection of a unified Korea based on the reconstructed population of North Korea provided in this work. Future work will also produce various aging indices and dependent ratios for a series of time schedules of unification to assess the population aging speed or degree and economic potentiality for a unified Korea. 


\section{References}

Adlakha, A. and West, L. (1997). An Analysis of DPRK 1993 Population Census Data and Population Projections, U.S. Census Bureau, unpublished.

Brass, W. (1977). On the scale of mortality, Biological Aspects of Demography, Taylor \& Francis.

Coale, A. J. and Demeny, P. (1983). Regional Model Life Tables and Stable Populations, Academic Press, New York.

DPRK Central Bureau of Statistics (2000). Report on the Second Multiple Cluster Indicator Survey 2000, Pyongyang.

DPRK Central Bureau of Statistics (2004). Report on the DPRK Reproductive Health Survey 2004, Pyongyang.

DPRK Central Bureau of Statistics (2007). Report on the DPRK Reproductive Health Survey 2006, Pyongyang.

Dyson, T. and Cormac, O. G. (2002). Famine Demography: Perspectives from the Past and Present, Oxford University Press, Oxford.

Engracia, L. (2010). UNFPA's Role in the DPRK's 2008 Population Census, The United Nations Foundation.

Food and Agriculture Organization-World Food Programme (FAO/WFP) (2010). Crop and Food Security Assessment Mission to the Democratic People's Republic of Korea, Special Report, November 16. http://www.fao.org/docrep/013/al968e00.htm

Goodkind, D. (1999). Do parents prefer sons in North Korea?, Studies in Family Planning, 30, 212 218.

Goodkind, D. and West, L. (2001). The North Korean famine and its demographic impact, Population and Development Review, 27, 219-238.

Goodkind, D., West, L. and Johnson, P. (2011). A reassessment of mortality in North Korea, 19932008. paper presented at the Annual Meeting of the Population Association of America March 31-April 2, Washington, D.C.

Greville, T. N. E. (1945). Actuarial note: Some extensions of Mr. Beers's method of interpolation, American Institute of Actuaries, 34, 21-34.

Haggard, S. and Noland, M. (2007). Famine in North Korea: Markets, Aid, and Reform, Columbia University Press, New York.

Hill, K. (1987). Estimating census and death registration completeness, Asian and Pacific Population Forum, 1, 8-24.

Jeon, S., Kim, S. and Park, Y. (2012). Quality evaluation of census and vital statistics of Korea using demographic analysis, The Korean Association for Survey Research, 13, 1-31.

Lee, S. (2004). The famine in North Korea, 1994-2000: outbreak, impact, and character, The Korea Institute for National Unification.

Moon, H. E. (2011). Democratic People's Republic of Korea in view of Demography (Japanese), Myungsuk Press.

Park, Y., Jang, S. and Kim, S. (2013). VECM-LC model for forecasting mortality in Korea, The Korean Association for Survey Research, 14, 19-47.

Park, Y. and Kim, S. (2011). A method for construction of life table in Korea, The Korean Journal of Applied Statistics, 12, 1-26.

Robinson, W. C., Lee, M. K., Hill, K. and Burnham, G. M. (1999). Mortality in North Korean migration households: A retrospective study, The Lancet, 354(9175), 291-295.

Spoorenberg, T. and Schwekendiek, D. (2012). Demographic changes in North Korea: 1993-2008, 
Population and Development Review, 38, 133-158.

Statistics Korea (2011). 1993-2055 Population Projection of North Korea, http://kosis.kr/statisticsList. United Nations (1983). Manual X: Indirect Techniques for Demographic Estimation.

Received September 10, 2014; Revised October 10, 2014; Accepted October 20, 2014 